\title{
Effects of check dams on runoff characteristics along gully reaches, the case of Northern Ethiopia
}

Etefa Guyassa (1,2), Amaury Frankl (1), Amanuel Zenebe (2), Jean Poesen (3), and Jan Nyssen (1)

(1) Ghent University, Department of Geography, Gent, Belgium (etefaguyassa.dinssa@ugent.be), (2) Mekelle University, Department of Land Resources Management and Environmental Protection, Mekelle, Ethiopia, (3) KULeuven, Department of Earth and Environmental Sciences, Leuven, Belgium

In the Highlands of Northern Ethiopia soil and water conservation (SWC) practices, including construction of check dams in gullies, have been widely implemented for the last three decades. Despite this extensive installation of check dams, their effects on runoff response are not well understood as compared to those of other SWC practices. Hence, this study examines the effects of check dams on runoff response in gully channels. 90 degree V-notch weirs were installed to measure a wide range of runoff discharges at the upper and lower sections of five gully reaches: two channel cut in sandstone (a gully with check dams and vegetation (SCV) and an untreated gully (S)) and three cut in limestone (an untreated gully (L), a gully with check dams but no vegetation (LC) and a gully with check dams and vegetation (LCV)). Automatic sensors were installed to monitor runoff depth during two rainy seasons (29/08/14 - 17/09/14 and 24/7/15 - 14/09/15). All runoff characteristics at the lower section of each gully reaches were calculated for a gully reaches length of $50 \mathrm{~m}$. In the sandstone area, the results show longer lag times of runoff to reach the lower section of the channel reach in the treated gully (SCV) compared to the untreated gully: difference in time lag equal lag to production of runoff equals $51 \%$ for runoff initiation, $61 \%$ for peak runoff and $44 \%$ for runoff end. An increase of hydraulic roughness by check dams and water transmission losses in deposited sediments are responsible for the delay of runoff to reach the lower part of the gully channels. In the limestone area, different time lags were recorded in different gully reaches regardless of the treatment effects (lag to runoff initiation, lag to peak flow and lag to runoff end were larger at LC, L and LCV, respectively). The reduction of peak runoff discharge between the upper and lower gully sections was larger in the gullies with check dam and vegetation $(8 \%-17 \%)$ than in gullies without treatment $(5 \%-6 \%)$. Reduction of runoff volume between these 2 gully sections was also larger in treated gullies than in untreated gullies: i.e. $18 \%, 9 \%$ and $8 \%$ in SCV, LCV and LC, respectively while it was only $4 \%$ in S and 6\% in L. This study shows that the implementation of check dams combined with vegetation reduced peak flow discharge and runoff volume as large sections of runoff infiltrated in the sediments deposited behind the check dams. As gully check dams are implemented in a large areas of the North Ethiopia Highlands, this contributes to groundwater recharge and increased river baseflows. 